Pacific Journal of Mathematics

THE SPECTRUM OF AN EQUATIONAL CLASS O 


\section{THE SPECTRUM OF AN EQUATIONAL CLASS OF GROUPOIDS}

\section{J. Froemke and R. Quackenbush}

The spectrum of an equational class $\mathscr{K}$ is the set of positive integers $\operatorname{Spec}(\mathscr{K})=\{n|\exists \mathscr{U} \in \mathscr{K},| \mathfrak{X} \mid=n\} . \quad$ It is obvious that $1 \in$ $\operatorname{Spec}(\mathscr{K})$ and $x, y \in \operatorname{Spec}(\mathscr{K})$ implies $x y \in \operatorname{Spec}(\mathscr{K})$ for any equational class $\mathscr{K}$; i.e. $\operatorname{Spec}(\mathscr{K})$ is a multiplicative monoid of positive integers. Conversely, G. Grätzer showed that given any multiplicative monoid of positive integers $\mathscr{S}$ there is an equational class $\mathscr{K}$ such that $\mathscr{S}=\operatorname{Spec}(\mathscr{K})$. In this paper we show that $\mathscr{K}$ can be chosen to be an equational class of groupoids.

Our first step is to give a simplified proof of Grätzer's theorem. For $n \geqq 1$ let $A_{n}=\{0,1, \cdots, n\}$. Define the function $p(x)$ on $A_{n}$ by $p(x)=x+1(\bmod n+1)$. Let $t(x, y, z)$ be the ternary discriminator function (t.d.f.) on $A_{n}$; i.e. $t(x, y, z)=z$ if $x=y$ and $t(x, y, z)=x$ if $x \neq y$. If the reader is not familiar with the properties of $t(x, y, z)$ he should consult [6]; for the concepts and notations of universal algebra see [2]. Let $\mathfrak{A}_{n}=\left\langle A_{n} ; t, p\right\rangle$.

Theorem 1. (G. Grätzer [1]). Let $\mathscr{S}$ be a multiplicative monoid of positive integers. There is an equational class $\mathscr{K}$ of type $\langle 3,1\rangle$ such that $\operatorname{Spec}(\mathscr{K})=\mathscr{S}$.

Proof. Let $\mathscr{K}^{\prime}=\left\{\mathfrak{A}_{n-1}^{\prime} \mid n \in \mathscr{S}-\{1\}\right\}$ and let $\mathscr{K}=H S P\left(\mathscr{K}^{\prime}\right)$. Because the t.d.f. is represented by $t(x, y, z)$ on each $\mathfrak{A}_{i}, \mathscr{K}$ has distributive congruences. Hence by the well known theorem of B. Jónsson [3] we have that $\mathscr{K}=P_{S} H S P_{P}\left(\mathscr{K}^{\prime}\right)$. In particular the subdirectly irreducible members of $\mathscr{K}$ are contained in $H S P_{P}\left(\mathscr{K}^{\prime}\right)$. Let $\mathfrak{U}^{\prime}$ be a prime product of members of $\mathscr{K}^{\prime}$, say $\left\{\mathfrak{U}_{j} \mid j \in J\right\}$ (the reader is referred to [2] for properties of prime products). If $\mathfrak{U}^{\prime}$ is finite then it is isomorphic to some $\mathfrak{A}_{j}$. Thus let $\mathfrak{U}^{\prime}$ be infinite. Since $t(x, y, z)$ represents the t.d.f. on $\mathfrak{U}^{\prime}$, all subalgebras of $\mathfrak{U}^{\prime}$ are simple. Using $p(x)$ we can form a sentence $\sigma_{n}$ in the first order theory of $\mathscr{K}$ which implies the existence of at least $n$ distinct elements and which is true in $\mathfrak{A}_{m}$ for $m \geqq$ $n-1$. Since $\mathfrak{U}^{\prime}$ is infinite, $\sigma_{n}$ is true in almost all members of $\left\{\mathfrak{A}_{j} \mid j \in J\right\}$ and so $\sigma_{n}$ is true in $\mathfrak{U}^{\prime}$ for all $n$. Hence every subalgebra of $\mathfrak{A}^{\prime}$ is infinite. This means that the finite subdirectly irreducible members of $\mathscr{K}$ are contained in $H S\left(\mathscr{F}_{i}^{\prime}\right)$. But each $\mathfrak{A}_{i} \in \mathscr{K}^{\prime}$ is simple and has no proper subalgebras. Hence up to isomorphism the finite subdirectly 
irreducible members of $\mathscr{K}$ are the members of $\mathscr{K}^{\prime}$. Finally we note that because of $t(x, y, z), \mathscr{K}$ has permutable congruences. Since each $\mathfrak{U}_{i} \in \mathscr{K}^{\prime}$ is simple this means that every finite algebra in $\mathscr{K}$ is a direct product of algebras from $\mathscr{K}^{\prime}$ so that $\mathscr{S}=\operatorname{Spec}(\mathscr{K})$ and the theorem is proved.

COROLlaRY 1. Let $\left\{\mathfrak{U}_{n} \mid n \geqq 1\right\}$ be algebras of type $\tau$ with $\left|\mathfrak{A}_{n}\right|=$ $n+1$. Let $t(x, y, z)$ and $p(x)$ be polynomials of type $\tau$ such that $t(x, y, z)$ represents the t.d.f. on each $\mathfrak{U}_{n}$ and $p(x)=x+1(\bmod n+1)$ in each $\mathfrak{U}_{n}$. Given any multiplicative monoid of positive integers $\mathscr{S}$ there is an equational class $\mathscr{K}$ of type $\tau$ such that $\mathscr{S}=\operatorname{Spec}(\mathscr{K})$.

Proof. Note that the proof of Theorem 1 only requires that $t(x, y, z)$ and $p(x)$ be polynomials, not that they be operations.

Thus we need to construct a set of groupoids $\left\{\mathfrak{B}_{n}\right\}$ satisfying the conditions of Corollary 1. First we will construct $\left\{\mathfrak{B}_{n} \mid n \geqq 3\right\}$ and later construct $\mathfrak{B}_{1}$ and $\mathfrak{B}_{2}$. The multiplication table for $\mathfrak{B}_{n}=\langle\{0,1, \cdots, n\} ; \omega\rangle$ for $n \geqq 3$ is given in Fig. 1 .

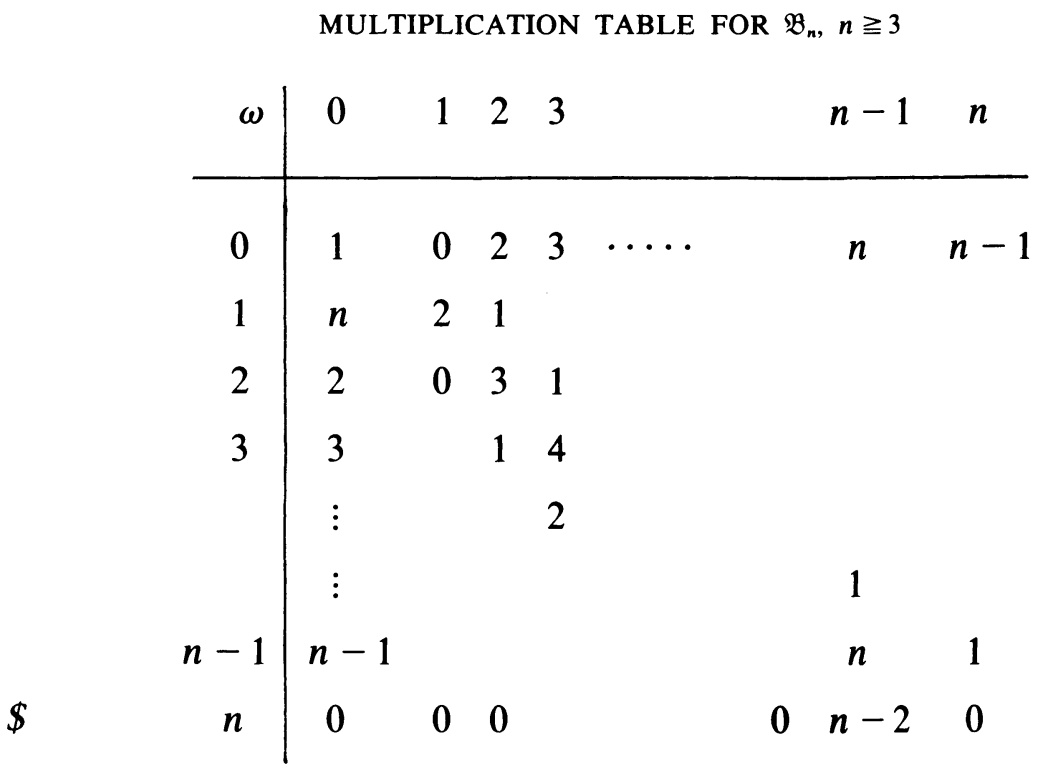

FIGURE 1

The multiplication table is filled in according to the following rules; the reader should check that for $n \geqq 3$ these rules are consistent (all addition is $\bmod n+1)$ :

(1) $\omega(x, x)=x+1$ for all $x$.

(2) $\omega(x+1, x)=x-1$ for all $x$. 
(3) $\omega(0,1)=\omega(n, 0)=0 ; \omega(x, x+1)=1$ for $x \neq 0, n$.

(4) $\omega(n, x)=0$ for $x \neq 0, n-1, n$.

(5) $\omega(0, n-1)=n ; \omega(0, x)=x$ for $x \neq 0,1, n-1, n$.

(6) $\omega(x, 0)=x$ for $x \neq 0,1, n$.

(7) In all other cases, $\omega(x, y) \neq 1$.

LeMMA 1. There are groupoid polynomials $t^{\prime}(x, y, z)$ and $p(x)$ such that $t^{\prime}(x, y, z)$ represents the t.d.f. on each $\mathfrak{A}_{n}, n \geqq 3$ and such that $p(x)=x+1(\bmod n+1)$ in $\mathfrak{U}_{n}, n \geqq 3$.

Proof. The proof will consist of a list of definitions of polynomials together with their values on $\mathfrak{A}_{n}$. The reader should have no trouble verifying each member of the list.

(1) $\alpha(x) \equiv \omega(x, x)=x+1$. Thus $p(x)=\alpha(x)$.

(2) $\beta(x) \equiv \omega(\alpha(x), x)=x-1$.

(3) $\gamma(x) \equiv \omega(x, \alpha(x))= \begin{cases}0 & \text { if } x=0, n, \\ 1 & \text { otherwise. }\end{cases}$

(4) $C_{1}(x) \equiv \gamma(\alpha(\gamma(x)))=1$.

(5) $\quad C_{0}(x) \equiv \beta\left(C_{1}(x)\right)=0 ; C_{n}(x) \equiv \beta\left(C_{0}(x)\right)=n$.

(6) $\delta_{n-1}(x) \equiv \gamma\left(\omega\left(C_{n}(x), x\right)\right)= \begin{cases}1 & \text { if } x=n-1, \\ 0 & \text { otherwise. }\end{cases}$

(7) $\delta_{n}(x) \equiv \delta_{n-1}(\beta(x))= \begin{cases}1 & \text { if } x=n, \\ 0 & \text { otherwise; }\end{cases}$ $\delta_{0}(x)=\delta_{n}(\beta(x))= \begin{cases}1 & \text { if } x=0, \\ 0 & \text { otherwise. }\end{cases}$

(8) $\delta_{k}(x) \equiv \delta_{0}\left(\beta^{k}(x)\right)= \begin{cases}1 & \text { if } x=k, \\ 0 & \text { otherwise. }\end{cases}$

(9) $\quad \bar{\delta}_{j}(x) \equiv \delta_{0}\left(\delta_{j}(x)\right)= \begin{cases}0 & \text { if } x=j \\ 1 & \text { otherwise }\end{cases}$

(10) $\Delta_{j, k}(x, y) \equiv \delta_{0}\left(\omega\left(\overline{\delta_{j}}(x), \delta_{k}(y)\right)\right)=\left\{\begin{array}{l}1 \text { if }(x, y)=(j, k), \\ 0 \text { otherwise. }\end{array}\right.$

(11) $\bar{\Delta}_{j, k}(x, y) \equiv \delta_{0}\left(\Delta_{j, k}(x, y)\right)=\left\{\begin{array}{l}0 \text { if }(x, y)=(j, k), \\ 1 \text { otherwise }\end{array}\right.$

(12) $\omega(0, \omega(0, y))=y$ and $\omega(n, \omega(n, y))=0$.

(13) $x \cdot y \equiv \alpha\left(\omega\left(\beta\left(\delta_{0}(x)\right), \omega\left(\beta\left(\delta_{0}(x)\right), \beta(y)\right)\right)\right)$.

(14) $1 \cdot y=1,0 \cdot y=y$.

(15) $\sigma(x) \equiv \omega\left(C_{0}(x), x\right) ; \sigma^{2}(x)=x$.

(16) $\tau(x) \equiv \omega\left(x, C_{0}(x)\right) ; \tau^{3}(x)=x$.

(17) $x+y \equiv \omega\left(\tau^{2}(x), \sigma(y)\right) ; 1+y=y+1=y$.

(18) $\omega(x, \alpha(y))=1$ iff $(x=y$ and $x \neq 0, n)$ or $((x, y)=(0, n))$ or $((x, y)=(3,1))$.

(19) $\bar{\varepsilon}(x, y) \equiv \bar{\Delta}_{0,0}(x, y)$

$$
+\left(\bar{\Delta}_{n, n}(x, y)+\left(\Delta_{0, n}(x, y) \cdot\left(\Delta_{3,1}(x, y) \cdot \bar{\delta}_{1}(\omega(x, \alpha(y)))\right)\right)\right) .
$$


(20) $\bar{\varepsilon}(x, y)=\left\{\begin{array}{l}0 \text { if } x=y \\ 1 \text { otherwise. }\end{array}\right.$

$$
\begin{aligned}
& \varepsilon(x, y) \equiv \delta_{0}(\bar{\varepsilon}(x, y))= \begin{cases}1 & \text { if } x=y \\
0 & \text { otherwise. }\end{cases} \\
& t^{\prime}(x, y, z) \equiv(\bar{\varepsilon}(x, y) \cdot z)+(\varepsilon(x, y) \cdot x)= \begin{cases}z \text { if } x=y \\
x & \text { otherwise }\end{cases}
\end{aligned}
$$

This concludes the proof of Lemma 1 .

Each of the $\mathfrak{B}_{n}, n \geqq 3$, is a primal algebra (i.e. a finite nontrivial algebra such that every function on the algebra is representable by a polynomial). A theorem of E. S. O'Keefe [4] asserts that a set of pairwise nonisomorphic primal algebras of a type consisting of just one operation is independent. In particular this guarantees that for any finite subset of $\left\{\mathfrak{B}_{n}\right\}$ there is a polynomial representing the t.d.f. However, this does not guarantee that there is a polynomial representing the t.d.f. on all $\mathfrak{B}_{n}$.

Now consider $\mathfrak{B}_{1}$ and $\mathfrak{B}_{2}$ as given in Fig. 2. It is well known that $\mathfrak{B}_{1}$ is primal. To see that $\mathfrak{B}_{2}$ is primal we invoke a theorem of $G$. Rousseau [7] which states that if $\mathfrak{A}$ is a finite nontrivial algebra of type $\langle n\rangle$ with $n \geqq 2$ then $\mathfrak{U}$ is primal iff $\mathfrak{U}$ has no proper subalgebras, has no proper automorphisms, and is simple. It will be shown shortly that every element of $\mathfrak{B}_{2}$ is the value of a constant polynomial. Hence the first two conditions hold. To see that $\mathfrak{B}_{2}$ is simple note that if $0 \equiv 1$ then $0=\omega(0,1) \equiv \omega(1,1)=2$; if $0 \equiv 2$ then $1=\omega(0,0) \equiv \omega(2,0)=2$, and if $1 \equiv 2$ then $0=\omega(0,1) \equiv \omega(0,2)=1$. Hence $\mathfrak{B}_{2}$ is primal. Thus by the above mentioned theorem of O'Keefe there is a polynomial $t^{\prime \prime}(x, y, z)$ representing the t.d.f. on $\mathfrak{B}_{1}$ and $\mathfrak{B}_{2}$.

\begin{tabular}{l|ll}
$\omega$ & 0 & 1 \\
\hline 0 & 1 & 1 \\
1 & 1 & 0
\end{tabular}

$\mathfrak{B}_{1}$

\begin{tabular}{l|lll}
$\omega$ & 0 & 1 & 2 \\
\hline 0 & 1 & 0 & 1 \\
1 & 1 & 2 & 0 \\
2 & 2 & 1 & 0
\end{tabular}

$\mathfrak{B}_{2}$

Figure 2

Lemma 2. There is a polynomial $\phi(x, y)$ such that $\phi(x, y)=x$ in $\mathfrak{B}_{1}, \mathfrak{B}_{2}$ while $\phi(x, y)=y$ in $\mathfrak{A}_{n}, n \geqq 3$.

Proof. Again we make a series of definitions and statements each of which is easily verifiable. 
(1) $\alpha(x) \equiv \omega(x, x)=x+1$ in $\mathfrak{B}_{n}, n \geqq 1$.

(2) $\beta(x) \equiv \omega(\alpha(x), x)= \begin{cases}1 & \text { in } \mathfrak{B}_{1}, \mathfrak{B}_{2}, \\ x-1 & \text { in } \mathfrak{B}_{n}, n \geqq 3 .\end{cases}$

(3) $\rho(x) \equiv \beta(\alpha(x))=\left\{\begin{array}{l}1 \text { in } \mathfrak{B}_{1}, \mathfrak{B}_{2}, \\ x \text { in } \mathfrak{B}_{n}, n \geqq 3 .\end{array}\right.$

(4) $\quad \alpha^{\prime}(x) \equiv \omega(\rho(x), x)=\left\{\begin{array}{l}\text { a permutation in } \mathfrak{B}_{1}, \mathfrak{B}_{2}, \\ \alpha(x) \text { in } \mathfrak{B}_{n}, n \geqq 3 .\end{array}\right.$

(5) $\quad \beta^{\prime}(x) \equiv \omega(\alpha(x), \rho(x))=\left\{\begin{array}{l}\text { a permutation in } \mathfrak{B}_{1}, \mathfrak{B}_{2}, \\ \beta(x) \text { in } \mathfrak{B}_{n}, n \geqq 3 .\end{array}\right.$

(6) $\gamma^{\prime}(x) \equiv \omega\left(\rho(x), \alpha^{\prime}(x)\right)=\left\{\begin{array}{l}\text { a permutation in } \mathfrak{B}_{1}, \mathfrak{B}_{2}, \\ \gamma(x) \text { in } \mathfrak{B}_{n}, n \geqq 3 .\end{array}\right.$

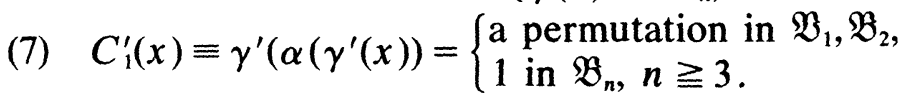

(8) $C_{0}^{\prime}(x) \equiv \beta^{\prime}\left(C_{1}^{\prime}(x)\right)=\left\{\begin{array}{l}\text { a permutation in } \mathfrak{B}_{1}, \mathfrak{B}_{2} \text {, } \\ 0 \text { in } \mathfrak{B}_{n}, n \geqq 3 \text {. }\end{array}\right.$

(9) Compose $C_{0}^{\prime}(x)$ with itself sufficiently many times to get $\eta(x)=\left\{\begin{array}{l}x \text { in } \mathfrak{B}_{1}, \mathfrak{B}_{2}, \\ 0 \text { in } \mathfrak{B}_{n}, n \geqq 3 .\end{array}\right.$

(10) $\mu(x, y) \equiv \omega(\eta(x), \rho(y))$ $=\left\{\begin{array}{l}\text { a permutation in } x \text { of order } 2 \text { in } \mathfrak{B}_{1}, \mathfrak{B}_{2}, \\ \text { a permutation in } y \text { of order } 2 \text { in } \mathfrak{B}_{n}, n \geqq 3 .\end{array}\right.$

(11) $\phi(x, y) \equiv \mu(\mu(x, y), \mu(x, y))=\left\{\begin{array}{l}x \text { in } \mathfrak{B}_{1}, \mathfrak{B}_{2}, \\ y \text { in } \mathfrak{B}_{n}, n \geqq 3 .\end{array}\right.$

This concludes the proof of Lemma 2 .

THEOREM 2. Given any multiplicative monoid of positive integers $\mathscr{S}$ there is an equational class of groupoids $\mathscr{K}$ such that $\mathscr{S}=$ $\operatorname{Spec}(\mathscr{K})$. If $\mathscr{S} \neq\{1\}$ then there are uncountably many such equational classes of groupoids and each is generated by its finite members.

Proof. Let $\left\{\mathfrak{B}_{n} \mid n \geqq 1\right\}$ be as defined in Fig. 1 and 2. Let $\mathscr{K}^{\prime}=$ $\left\{\mathfrak{B}_{n-1} \mid n \in \mathscr{S}-\{1\}\right\}$ and let $\mathscr{K}=H S P\left(\mathscr{K}^{\prime}\right)$. Then taking $p(x)=\alpha(x)$ and $t(x, y, z)=\phi\left(t^{\prime \prime}(x, y, z), t^{\prime}(x, y, z)\right)$ we see that by Corollary $1, \mathscr{S}=$ $\operatorname{Spec}(\mathscr{K})$. If $\mathscr{S} \neq 1$ let $m \in \mathscr{S}$ with $m>1$. Then for $n>1$ we can include or exclude $B m^{n}$ from $\mathscr{K}^{\prime}$ without changing the spectrum of $\operatorname{HSP}\left(\mathscr{K}^{\prime}\right)$.

Problem 1. For which equational subclasses of groupoids does Theorem 2 hold? It is known to be false for semigroups. If we consider idempotent groupoids, note that there are up to isomorphism, only three two element idempotent groupoids and any equational class containing one of them has a complete spectrum: all positive integers. For $2 \notin \mathscr{S}$ it is likely that there is an equational class of idempotent groups whose spectrum is $\mathscr{S}$. 
Problem 2. If $\mathscr{S}$ is finitely generated then we may take $\mathscr{K}^{\prime}$ to consist only of those $\mathfrak{B}_{n-1}$ for $n$ in a given finite generating set of $\mathscr{S}$. Thus $\mathscr{K}$ will be generated by a finite algebra (the product of the $\left.\mathfrak{B}_{n-1}\right)$. Hence by a result of Kirby Baker, $\mathscr{K}$ is finitely based and so by [5] 1-based. On the other hand, if $\mathscr{K}$ is finitely based then necessarily $\mathscr{S}$ is recursive. Is the converse true; namely if $\mathscr{S}$ is recursive is the corresponding $\mathscr{K}$ finitely based?

\section{REFERENCES}

1. G. Gratzer, On the spectra of classes of algebras, Proc. Amer. Math. Soc., 18(1967), 729-735.

2. - Universal Algebra, Van Nostrand, Princeton, 1968.

3. B. Jonsson, Algebras whose congruence lattices are distributive, Math. Scand., 21 (1967), 110-121.

4. E. S. O'Keefe, On the independence of primal algebras, Math. Z., 73 (1960), 79-94.

5. R. Padmanabhan and R. Quackenbush, Equational theories of algebras with distributive congruences, Proc. Amer. Math. Soc., 41 (1973), 373-377.

6. A. Pixley, The ternary discriminator function in universal algebra, Math. Ann., 191 (1971), 167-180.

7. G. Rousseau, Completeness in finite algebras with a single operation, Proc. Amer. Math. Soc., 18 (1967), 1009-1013.

Received March 26, 1974. The work of the second author was supported by a grant from the National Research Council of Canda.

OAKLAND UNIVERSITY

AND

UNIVERSITY OF MANITOBA 


\section{PACIFIC JOURNAL OF MATHEMATICS}

\section{EDITORS}

RICHARD ARENS (Managing Editor)

University of California

Los Angeles, California 90024

\section{J. DugundJI}

Department of Mathematics University of Southern California Los Angeles, California 90007

D. Gilbarg and J. Milgram

Stanford University

Stanford, California 94305

\section{ASSOCIATE EDITORS}
E. F. BECKENBACH
B. H. NeumanN
F. WoLF
K. YoshiDA

\section{SUPPORTING INSTITUTIONS}

\author{
UNIVERSITY OF BRITISH COLUMBIA \\ CALIFORNIA INSTITUTE OF TECHNOLOGY \\ UNIVERSITY OF CALIFORNIA \\ MONTANA STATE UNIVERSITY \\ UNIVERSITY OF NEVADA \\ NEW MEXICO STATE UNIVERSITY \\ OREGON STATE UNIVERSITY \\ UNIVERSITY OF OREGON \\ OSAKA UNIVERSITY
}

\author{
UNIVERSITY OF SOUTHERN CALIFORNIA \\ STANFORD UNIVERSITY \\ UNIVERSITY OF TOKYO \\ UNIVERSITY OF UTAH \\ WASHINGTON STATE UNIVERSITY \\ UNIVERSITY OF WASHINGTON \\ AMERICAN MATHEMATICAL SOCIETY
}

The Supporting Institutions listed above contribute to the cost of publication of this Journal, but they are not owners or publishers and have no responsibility for its contents or policies.

Mathematical papers intended for publication in the Pacific Journal of Mathematics should be in typed form or offset-reproduced (not dittoed), double spaced with large margins. Underline Greek letters in red, German in green, and script in blue. The first paragraph or two must be capable of being used separately as a synopsis of the entire paper. Items of the bibliography should not be cited there unless absolutely necessary, in which case they must be identified by author and Journal, rather than by item number. Manuscripts, in duplicate, may be sent to any one of the four editors. Please classify according to the scheme of Math. Reviews, Index to Vol. 39. All other communications should be addressed to the managing editor, or Elaine Barth, University of California, Los Angeles, California, 90024.

100 reprints are provided free for each article, only if page charges have been substantially paid. Additional copies may be obtained at cost in multiples of 50 .

The Pacific Journal of Mathematics is issued monthly as of January 1966. Regular subscription rate: $\$ 72.00$ a year (6 Vols., 12 issues). Special rate: $\$ 36.00$ a year to individual members of supporting institutions.

Subscriptions, orders for back numbers, and changes of address should be sent to Pacific Journal of Mathematics, 103 Highland Boulevard, Berkeley, California, 94708.

PUBLISHED BY PACIFIC JOURNAL OF MATHEMATICS, A NON-PROFIT CORPORATION Printed at Jerusalem Academic Press, POB 2390, Jerusalem, Israel.

$$
\begin{gathered}
\text { Copyright (C) } 1975 \text { Pacific Journal of Mathematics } \\
\text { All Rights Reserved }
\end{gathered}
$$




\section{Pacific Journal of Mathematics}

\section{Vol. 58, No. $2 \quad$ April, 1975}

Zvi Artstein and John Allen Burns, Integration of compact set-valued functions . . . . . . . . . 297

Mark Benard, Characters and Schur indices of the unitary reflection group $[321]^{3} \ldots \ldots \ldots . .309$

Simeon M. Berman, A new characterization of characteristic functions of absolutely continuous

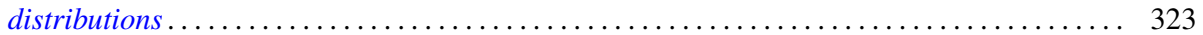

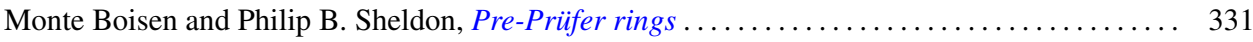

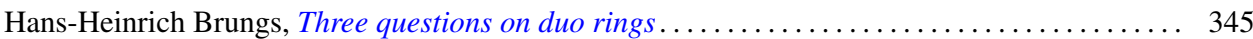

Iracema M. Bund, Birnbaum-Orlicz spaces of functions on groups................. 351

John D. Elwin and Donald R. Short, Branched immersions between 2-manifolds of higher

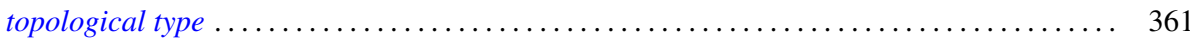

Eric Friedlander, Extension functions for rank 2, torsion free abelian groups . .......... 371

Jon Froemke and Robert Willis Quackenbush, The spectrum of an equational class of

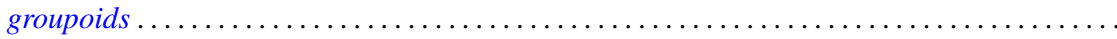

Barry J. Gardner, Radicals of supplementary semilattice sums of associative rings ...........

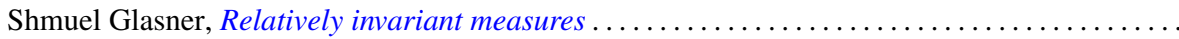

George Rudolph Gordh, Jr. and Sibe Mardesic, Characterizing local connectedness in inverse

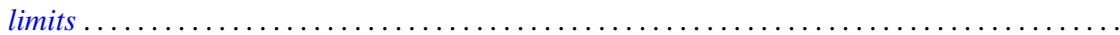

Siegfried Graf, On the existence of strong liftings in second countable topological spaces......

Stanley P. Gudder and D. Strawther, Orthogonally additive and orthogonally increasing

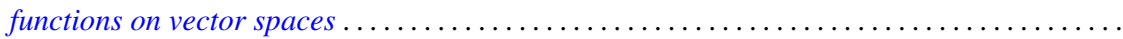

Darald Joe Hartfiel and Carlton James Maxson, A characterization of the maximal monoids and

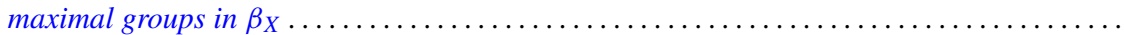

Robert E. Hartwig and S. Brent Morris, The universal flip matrix and the generalized faro-shuffle. .

William Emery Haver, Mappings between ANRs that are fine homotopy equivalences. .

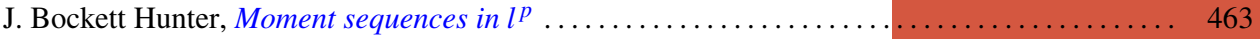

Barbara Jeffcott and William Thomas Spears, Semimodularity in the completion of a poset.... 467

Jerry Alan Johnson, A note on Banach spaces of Lipschitz functions . . . . . . . . . . . . 475

David W. Jonah and Bertram Manuel Schreiber, Transitive affine transformations on

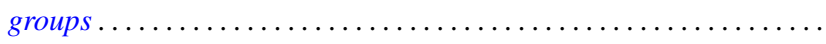

Karsten Juul, Some three-point subset properties connected with Menger's characterization of

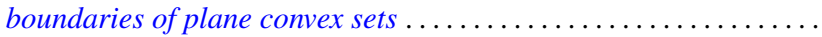

Ronald Brian Kirk, The Haar integral via non-standard analysis . . . . . . . . . . . . . 517

Justin Thomas Lloyd and William Smiley, On the group of permutations with countable

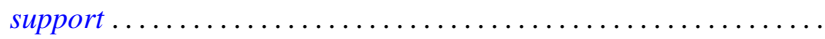

Erwin Lutwak, Dual mixed volumes .................................. 531

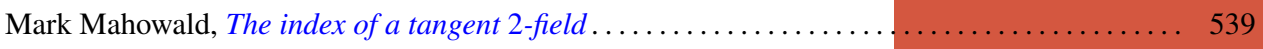

Keith Miller, Logarithmic convexity results for holomorphic semigroups . . . . . . . . . . . . 549

Paul Milnes, Extension of continuous functions on topological semigroups . . . . . . . . . . 553

Kenneth Clayton Pietz, Cauchy transforms and characteristic functions ................ 563

James Ted Rogers Jr., Whitney continua in the hyperspace $C(X) \ldots \ldots \ldots \ldots \ldots \ldots \ldots \ldots .569$

Jean-Marie G. Rolin, The inverse of a continuous additive functional . . . . . . . . . . . . 585

William Henry Ruckle, Absolutely divergent series and isomorphism of subspaces . ........ 605

Rolf Schneider, A measure of convexity for compact sets . ..................... 617

Alan Henry Schoenfeld, Continous measure-preserving maps onto Peano spaces .......... 627

V. Merriline Smith, Strongly superficial elements .......................... 643

Roger P. Ware, A note on quadratic forms over Pythagorean fields . . . . . . . . . . . . . . 651

Roger Allen Wiegand and Sylvia Wiegand, Finitely generated modules over Bezout rings . . . . 655

Martin Ziegler, A counterexample in the theory of definable automorphisms . . . . . . . . . 665 